\title{
Pattern of surgical admissions to Tikur Anbessa Specialized Hospital, Addis Ababa, Ethiopia: A five-year retrospective study
}

\author{
Sahlu Wondimu, Solomon Bekele, Dawit G. Giorgis, Feron Getachew, Nebyou Seyoum \\ Department of Surgery, College of Health Sciences, Addis Ababa University, Addis Ababa, Ethiopia \\ Correspondence: Dr Sahlu Wondimu (sahlu.wondimu@gmail.com)
}

\begin{abstract}
(c) 20185. Wondimu et al. This open access article is licensed under a (reative Commons Attribution 4.0 International License (http://creativecommons.org/licenses/by/4.0/) which permits unrestricted use, distribution, and reproduction in any medium, provided you give appropriate credit to the original author(s) and the source, provide a
\end{abstract} link to the Creative Commons license, and indicate if changes were made.

East Cent Afr J Surg. 2018 Aug;23(2):66-70 https://dx.doi.org/10.4314/ecajs.v23i2.3

\begin{abstract}
Background

Tikur Anbessa specialized hospital (TASH) is Ethiopia's largest tertiary teaching and referral hospital admitting and treating surgical patients under various specialties. This study aims to analyze the magnitude and pattern of surgical admissions to this facility.

Methods

A five-year Cross sectional retrospective analysis was done on all adult surgical admissions to TASH from Sept. 2010 to Sept. 2015.

\section{Results}

There were a total of 8,698 surgical admissions of which, 4471 (51.4\%) were male and 4227 (48.5\%) were female with male to female ratio of 1.06:1. Their age ranged from 13 to 95, with mean age being $38.8 \pm 16.2$ years. Three thousand two hundred twenty two (46.5\%) patients were from Addis Ababa. Of all admissions, 4706 (54.1\%) were elective ones of which obstructive uropathy, 997(21.1\%), esophageal diseases, 716(15.2\%) and Urolithiasis, 573(12.2\%) respectively are the top three. The rest, 3992 (44.9\%), were emergency admissions, the top three ones being trauma, 1435(35.9\%), appendicitis 281(7\%) and Intestinal obstruction, $190(4.7 \%)$ respectively. General surgical (gastrointestinal, endocrine and vascular) cases account for 3414 (39.25\%) of all admissions followed by urosurgical cases, 2114 (25.31\%), cardiothoracic surgical cases, 1942 (22.33\%), and neurosurgical cases, 1139 (13.1\%). There were a total of 280 deaths with an overall mortality rate of $4 \%$ of which, 3.2\% were from elective admissions and 5.2\% from emergency ones. Mortality rate was the highest among neurosurgical patients being $6.3 \%$ followed by $4.3 \%, 3.8 \%$ and $3.5 \%$ in cardiothoracic, general surgical and urosurgical cases respectively.
\end{abstract}

\section{Conclusions}

The admission pattern indicates quite a big number and diversity of cases though the bed capacity is limited. There are significant number of cases that could be treated at other secondary level hospitals. Trauma is the leading cause of emergency admissions and significant cause of mortality. We recommend increasing the number of beds, organizing separate trauma center and admitting only cases requiring tertiary level care.

Keywords: pattern of surgical diseases, surgical admissions, Tikur Anbessa specialized hospital

\section{Introduction}

TASH is the forerunner and largest public teaching and tertiary referral hospital in Ethiopia. Being so, the hospital receives patients coming from all four corners of the nation and surgical diseases and admissions take the major share of its activities. The hospital has a total of 520 beds of which $120(24 \%)$ are dedicated to surgical patients. In a study of patterns of surgical admissions to this same hospital during 1994-1997, ${ }^{1}$ the number of beds allotted to surgical patients was 250 . The reduction in bed capacity was due to the Open- ing of new other departments and expansion of existing ones. The department of surgery as it endeavors to take care of its patients is organized into different units namely General surgery including gastrointestinal, endocrine and vascular surgeries, urology, cardiothoracic surgery, Neurosurgery, plastic and reconstructive surgery and pediatric surgery. Despite the high number of surgical patients admitted and operated in the hospital, the pattern and magnitude of these surgical diseases is not recently described.

Although, analyzing hospital admissions doesn't reflect 
the pattern of surgical diseases at the community level, it can give base line information as to which of the prevailing surgical pathologies are the common causes of admissions and such information is helpful in policy making to prioritize and allocate the available meager human and material resources , in developing relevant under and post graduate curricula and train man power and also to compare with results of studies from other institutions. We therefore conducted this study to provide the latest information on patterns and magnitude of surgical admissions to TASH with these intensions in mind.

\section{Methods}

A five-year retrospective analysis of all the records of adult (age $>13$ ) surgical admissions to all surgical wards of TASH from September 2010 to September 2015 was done. The admissions to Pediatric, plastic and orthopedic surgical units were excluded. The specific surgical diseases are classified according to the WHO International classification of Diseases (ICD-10 v-1), 2013 edition. ${ }^{2}$ Study variables including demographic characteristics of patients, mode and unit of admission, diagnosis, length of stay and condition on discharge were extracted from the records using a pretested questionnaire and the data was analyzed using SPSS ver. 23 statistical software.

\section{Results}

There were a total of 8,698 surgical admissions of which 4471 (51.4\%) were males and 4227 (48.5\%) were females with overall male to female ratio of 1.06:1. Their age ranged from 13 to 95 , with a mean age of $38.8 \pm 16.2$ years. The majority of patients came from the capital Addis Ababa, 4044 (46.5\%) and a region around it, 2747 (31.5\%) (Table 1).

\begin{tabular}{lcc}
\hline \multicolumn{2}{c}{ Table 1. Home address by region of patients admitted to } \\
surgical wards of TASH from Sept. 2010 to Sept. 2015
\end{tabular}

\begin{tabular}{|c|c|c|c|}
\hline No. & Disease & No. & $\begin{array}{l}\text { Percent } \\
(\%)\end{array}$ \\
\hline 1 & Obstructive uropathy & 997 & 21.1 \\
\hline 2 & $\begin{array}{l}\text { Esophageal disease } \\
\text { (mainly carcinoma) }\end{array}$ & 716 & 15.2 \\
\hline 3 & Urolithiasis & 573 & 12.2 \\
\hline 4 & $\begin{array}{c}\text { Thyroid diseases(benign } \\
\text { and malignant) }\end{array}$ & 468 & 9.9 \\
\hline 5 & $\begin{array}{l}\text { Cholelithiasis/ } \\
\text { cholecystitits }\end{array}$ & 350 & 7.4 \\
\hline 6 & Colorectal diseases & 341 & 7.2 \\
\hline 7 & $\begin{array}{l}\text { Breast diseases (benign } \\
\text { and malignant) }\end{array}$ & 244 & 5.1 \\
\hline 8 & Bladder tumor & 216 & 4.6 \\
\hline 9 & Pleural diseases & 210 & 4.4 \\
\hline 10 & Vascular diseases & 172 & 3.6 \\
\hline
\end{tabular}

Four thousand seven hundred six (54.1\%) of the surgical admissions were admitted on elective basis whereas the rest 3992 (45.9\%) were emergency admissions. Obstructive uropathy 997 (21.1\%),Esophageal diseases 716 (15.2\%) and Urolithiasis $573(12.2 \%)$ are the three most common causes of elective admissions (Table 2). Trauma (neurotrauma, chest and abdominal trauma) is the leading cause of emergency admissions, 1435 (35.9\%) followed distantly by Appendicitis 281 (7\%), Intestinal obstruction 190 (4.7\%) and peritonitis of unspecified etiology, 110 (2.7\%). Neurotrauma (head and spinal injury) $864(60.2 \%)$ is the most frequent form of trauma followed by chest, 297 (20.7\%) and abdominal trauma 236 (16.4\%).

Admissions to the General surgery unit account for 3414 $(39.25 \%)$ of the cases followed by urosurgical cases 2114 (24.31\%), cardiothoracic surgical cases 1942 (22.33\%) and neurosurgical cases 1139 (13.1\%) (Table 3).

Benign diseases of the thyroid gland, 353 (10.7\%), cholelithiasis/cholecystitits $350(10.6 \%)$ and colorectal diseases, $341(10.3 \%)$ constitute the top three causes of elective admissions to the General surgery unit whereas Appendicitis, 281 (8.5\%), abdominal trauma, 236 (7.2\%) and intestinal obstruction $190(5.8 \%)$ are the most common causes of emergency admissions (Table 4).

Obstructive uropathy of different causes 997 (47.2\%), is the most common cause of urosurgical admission followed 


\begin{tabular}{lcc}
\hline \multicolumn{3}{c}{ Table 3. Surgical admissions to the different units of the } \\
department of surgery, TASH, Sept. & 2010 & Sept 2015 \\
\hline Unit of admission & No. & $\begin{array}{c}\text { Percent } \\
\text { (\%) }\end{array}$ \\
General surgery & 3414 & 39.25 \\
Urology & 2114 & 24.31 \\
Cardiothoracic & 1942 & 22.33 \\
Surgery & 1139 & 13.1 \\
Neurosurgery & 89 & 1.02 \\
ENT & 8698 & 100.0 \\
Total & 16 & 0.2 \\
Benishangul Gumuz & 8698 & 100.0 \\
\hline Total & & \\
\hline
\end{tabular}

\begin{tabular}{|c|c|c|}
\hline Disease & No. & $\begin{array}{c}\text { Percent } \\
(\%)\end{array}$ \\
\hline $\begin{array}{l}\text { Benign Thyroid } \\
\text { diseases }\end{array}$ & 353 & 10.7 \\
\hline $\begin{array}{l}\text { Cholelithiasis/ } \\
\text { cholecystitits }\end{array}$ & 350 & 10.6 \\
\hline Colorectal diseases & 341 & 10.3 \\
\hline Appendicitis & 281 & 8.5 \\
\hline Breast & 244 & 7.4 \\
\hline $\begin{array}{l}\text { Trauma (Blunt/ } \\
\text { penetrating) }\end{array}$ & 236 & 7.2 \\
\hline Intestinal obstruction & 190 & 5.8 \\
\hline Vascular diseases & 172 & 5.2 \\
\hline $\begin{array}{l}\text { PUD (GOO, } \\
\text { Perforation, bleeding) }\end{array}$ & 142 & 4.3 \\
\hline Obstructive jaundice & 133 & 4.0 \\
\hline $\begin{array}{l}\text { Malignant thyroid } \\
\text { diseases }\end{array}$ & 115 & 3.5 \\
\hline $\begin{array}{l}\text { Peritonitis } \\
\text { (Unspecified) }\end{array}$ & 110 & 3.3 \\
\hline Gastric cancer & 84 & 2.5 \\
\hline Hernia & 82 & 2.5 \\
\hline Perianal conditions & 59 & 1.8 \\
\hline Others & 406 & 12.3 \\
\hline Total & 3414 & 100.0 \\
\hline
\end{tabular}

by Urolithiasis (stones in the kidney, ureter and bladder), 573 (27.3\%) and Bladder tumor 216, (10.2\%) (Table 5).

Esophageal diseases mainly esophageal cancer, 716 $(37.7 \%)$ is the most common cause of elective admission to the cardiothoracic surgery unit followed by pleural diseases, $210(11.1 \%)$ and lung tumors $146(7.7 \%)$. Chest trauma, $297(15.6 \%)$ and foreign body swallowing and aspiration, 20 $(1.1 \%)$ are the major emergency admissions to this unit (Table 6).

\begin{tabular}{|c|c|c|}
\hline Disease & No. & $\begin{array}{l}\text { Percent } \\
(\%)\end{array}$ \\
\hline Obstructive uropathy & 997 & 47.2 \\
\hline Urolithiasis & 573 & 27.1 \\
\hline Bladder tumor & 216 & 10.2 \\
\hline GUT infections & 109 & 5.2 \\
\hline Renal tumors & 72 & 3.4 \\
\hline GUT Trauma & 38 & 1.8 \\
\hline Others & 109 & 5.2 \\
\hline Total & 2114 & 100 \\
\hline \multicolumn{3}{|c|}{$\begin{array}{l}\text { Table 6. Admissions to cardiothoracic surgery unit, Tikur } \\
\text { Anbessa Specialized Hospital, Sept. } 2010 \text { - Sept } 2015\end{array}$} \\
\hline Disease & No. & $\begin{array}{l}\text { Percent } \\
(\%)\end{array}$ \\
\hline Esophageal diseases & 716 & 37.7 \\
\hline Chest trauma & 297 & 15.6 \\
\hline Pleural Diseases & 210 & 11.1 \\
\hline Lung tumors & 146 & 7.7 \\
\hline Hydatid of the lung & 106 & 5.6 \\
\hline $\begin{array}{l}\text { Constrictive } \\
\text { pericarditis }\end{array}$ & 64 & 3.4 \\
\hline Mediastinal diseases & 62 & 3.3 \\
\hline Lung aspergillum & 56 & 2.9 \\
\hline PDA & 46 & 2.4 \\
\hline Chest wall mass & 44 & 2.3 \\
\hline Bronchiectasis & 41 & 2.2 \\
\hline lung abscess & 29 & 1.5 \\
\hline FB swallow, aspiration & 20 & 1.1 \\
\hline Others & 62 & 3.3 \\
\hline Total & 1942 & 100.0 \\
\hline
\end{tabular}


Two third (66.5\%) of neurosurgical admissions are emergency admissions due to Depressed skull fracture 216 (19.1\%), Chronic subdural hematoma 214 (18.9\%), Acute epidural hematoma $179(15.8 \%)$ and unspecified head injury $143(12.7 \%)$. Brain, spinal cord and pituitary tumors account only for $13.3 \%$ (150 cases) of neurosurgical admissions.

There was a total of 280 deaths with an overall mortality rate of $4 \%$.The mortality among emergency admissions is $5.6 \%$ and that of elective cases is $3.2 \%$. Mortality among neurosurgical admissions was $6.3 \%$ and is the highest of all the units followed by $4.3 \%, 3.8 \%$ and $3.5 \%$ in cardiothoracic, general surgical and urosurgical admissions respectively.

The total length of stay in the hospital ranged from 0.5 day- 125 days with an average of $12.3 \pm 11$ days.

\section{Discussion}

The study demonstrated that most of the surgical admissions were elective ones with predominantly male and relatively younger patients. A similar study done at the same hospital over two decades ago revealed the same tendency. ${ }^{1}$ This finding is also consistent with the report from Nigeria. ${ }^{3}$ However in a study from Pakistan, female surgical admissions predominate. ${ }^{4}$ Most surgical admissions came from the capital Addis Ababa and areas around it while only just over 20\% of them came from remote regions with referrals. This may partly explain why there are still many surgical admissions for cases that could have been admitted and treated at secondary level hospitals.

Obstructive uropathy, esophageal diseases mainly esophageal cancers and urolithiasis are found to be the three most common causes of elective admissions to the hospital. This is in contrast to the finding of the study from the same hospital during 1994-1997 when cholelithiasis, thyroid diseases and BPH were the most common causes of elective admissions. ${ }^{1}$ A recent study in Pakistan ${ }^{4}$ showed cholelithiasis and Inguinal hernia to be the common causes of elective admissions where as a relatively older study from the same country reported Hernia and an colorectal conditions as the two leading causes of elective admissions. ${ }^{5}$

Trauma is found to be the single most common cause of emergency admissions followed by appendicitis and intestinal obstruction. In a previous study from this same hospital, ${ }^{1}$ appendicitis and intestinal obstruction were listed as common causes of emergency admission. Trauma has evolved to be the common cause of emergency surgical admission over the years. This may be related to the significant growth of Addis Ababa as a modern metropolitan city with large number of vehicles and population density. A similar pattern of emergency admission was reported from Pakistan. ${ }^{5}$ Studies from Nigeria ${ }^{3}$ and Kenya ${ }^{6}$ also reported trauma to be the leading cause of all surgical admissions. In our study, neurotrauma (head and spinal injuries), chest and abdominal injuries are the most common forms of trauma unlike the Kenyan study which indicated soft tissue injuries, fractures and burns as the most common types of trauma. ${ }^{6}$

Among the units in our department, general surgery has the largest number of admissions followed by Urology and cardiothoracic units. Benign thyroid diseases, cholelithiasis and colorectal diseases are the top ranking causes of elective admissions to general surgery unit. Though there are some difficult cases, most of these diseases could have been treated at secondary level hospitals in and around the city. Esophageal diseases mainly esophageal cancer is the most common reason for elective admission to the cardiothoracic unit. A similar finding was reported by a study from this unit in $2013 .^{7}$ The majority ( $>66 \%$ ) of neurosurgical admissions were emergency ones due to trauma where depressed skull fractures and intracranial hematomas are the most common forms. Among all urologic admissions, obstructive uropathy and urolithiasis tops the list. Not all causes of obstructive uropathy are clearly defined in our sources of data. We think some of these undefined causes could be because of stones indicating the fact that the figure shown for obstructive uropathy could be an overestimate.

An overall mortality rate of $4 \%$ has been observed in our study. This is significantly lower than the $8 \%$ mortality rate reported in a similar study from the same hospital twenty years ago. ${ }^{1}$ Improvement in the level of medical care both in terms of highly trained manpower and facility is mainly responsible for this decline in mortality. Ours is also considerably lower than the overall mortality of $7.5 \%$ and $6.6 \%$ reported from Nigeria ${ }^{3}$ and Kenya, ${ }^{6}$ respectively. As expected most deaths (5.2\%) occurred among emergency admissions compared to only $3.2 \%$ of the deaths in elective admissions. The highest mortality rate (6.3\%) was observed among neurosurgical cases. As discussed earlier on, most of the neurosurgical admissions is due to trauma which appears to be among the leading causes of death. Similar finding was reported from the Kenyan study ${ }^{6}$ though malignancy was the most common cause of mortality in the Nigerian study. ${ }^{3}$

\section{Conclusions}

TASH admits a wide range of surgical conditions making it an ideal facility for all levels of surgical training though the bed capacity is limited. More than a third of elective admissions are due to obstructive uropathy and urolithiasis while trauma is the leading cause of emergency admissions. A significant number of admissions can be managed at other secondary level facilities.

We therefore recommend:

-Adequate expansion to provide more beds

- A separate trauma center equipped with relevant facilities and man power needs to be organized.

-Admit only cases that require tertiary level care

\section{Competing interests}

All authors declare that they have no competing interests related to this work. 


\section{References}

1. Adem A, Abebe A, Abdurahman M Pattern of surgical admissions to Tikur Anbessa hospital, Addis Ababa, Ethiopia, East Cent Afr J Surg. 2001;6(1).

2. World Health Organization (WHO). International statistical classification of diseases and related health problems. 10th ed. Geneva: WHO; 2011.

3. Alagoa PJ, Ukoima HS. Pattern of adult surgical admissions at the Niger Delta University Teaching Hospital, Okolobiri Bayelsa State - a 2 year review. Niger Health J 2014;14(4):183-7.
4. Zulfikar I, Zaheer F, Khaliq A, Jaleel F. Appraisal of general surgical admissions and procedures, influencing training of post graduate residents at newly developed tertiary care teaching hospital-Karachi. J Dow Univ Health Sci. 2015;9(3):112-6.

5. Junaid I, Qureshi H, Hasan A, Ahmed M. Pattern of admissions in a general surgical unit. J Pak Med Assoc. 1982 Aug:32(8):18790.
6. Masiira-Mukasa N, Ombito BR. Surgical admissions to the Rift Valley Provincial General Hospital, Kenya, East Afr Med J. 2002 Jul;79(7):373-8.

7. Teferra W, Kassa S, Ali A. Patterns of cardiothoracic and vascular surgical admissions at a tertiary university hospital Addis Ababa, Ethiopia. East Cent Afr J Surg. 2013;18(2):121-6. 